\title{
Fluorescence Studies on Potential Antitumoral Heteroaryl and Heteroannulated Indoles in Solution and in Lipid Membranes
}

\author{
Elisabete M. S. Castanheira • Ana S. Abreu • \\ M. Solange D. Carvalho • Maria-João R. P. Queiroz • \\ Paula M. T. Ferreira
}

Received: 7 August 2008 / Accepted: 3 November 2008 / Published online: 29 November 2008

(C) Springer Science + Business Media, LLC 2008

\begin{abstract}
Fluorescence properties of three potential antitumoral compounds, a 3-(dibenzothien-4-yl)indole 1, a phenylbenzothienoindole 2 and a 3-(dibenzofur-4-yl)indole 3 , were studied in solution and in lipid aggregates of dipalmitoyl phosphatidylcholine (DPPC), dioleoyl phosphatidylethanolamine (DOPE) and egg yolk phosphatidylcholine (Egg-PC). The 3-(dibenzofur-4-yl)indole 3 exhibits the higher fluorescence quantum yields in all solvents studied $\left(0.32 \leq \Phi_{\mathrm{F}} \leq 0.51\right)$. All the compounds present a solvent sensitive emission, with significant red shifts in alcohols. The results point to an ICT character of the excited state, more pronounced for compound 1. Fluorescence (steady-state) anisotropy measurements of the compounds incorporated in lipid aggregates of DPPC, DOPE and Egg-PC indicate that the three compounds are deeply located in the lipid bilayer, feeling the difference between the rigid gel phase and fluid phases.
\end{abstract}

Keywords Heteroaryl and heteroannulated indoles · Lipid membranes $\cdot$ Fluorescence anisotropy

\section{Abbreviations \\ DPPC dipalmitoyl phosphatidylcholine \\ DOPE dioleoyl phosphatidylethanolamine}

\footnotetext{
E. M. S. Castanheira $(\bowtie) \cdot$ A. S. Abreu

Centro de Física, Universidade do Minho,

Campus de Gualtar,

4710-057 Braga, Portugal

e-mail: ecoutinho@fisica.uminho.pt
}

\author{
A. S. Abreu • M. S. D. Carvalho • M.-J. R. P. Queiroz • \\ P. M. T. Ferreira \\ Centro de Química, Universidade do Minho, \\ Campus de Gualtar, \\ 4710-057 Braga, Portugal
}

\author{
Egg-PC egg yolk phosphatidylcholine \\ PC phosphatidylcholine \\ PE phosphatidylethanolamine
}

\section{Introduction}

For some years now our research group has synthesized a large variety of new fluorescent planar heteroaromatic compounds from dehydroamino acid derivatives, using metal-mediated reactions [1-3] and some of them were shown to be DNA intercalators [3].

Studies of incorporation in lipid vesicles using fluorescence techniques were also performed with biological active tetracyclic planar compounds derivatives of benzo[b]thiophenes and pyridines, a benzothienopyridopyrimidone [4] and a thieno- $\delta$-carboline [5], prepared by us. These studies are very useful for controlled drug release assays.

More recently, some of us have described the synthesis of new heteroaryl and heteroannulated indoles from dehydrophenylalanines, a methyl 3-(dibenzothien-4-yl)indole-2carboxylate 1, a methyl 1-phenyl-3H-benzothieno[2,3-e] indole-2-carboxylate 2, a methyl 3-(dibenzofur-4-yl)indole2-carboxylate 3 and a methyl 1-phenyl-3H-benzofuro[2,3-e] indole-2-carboxylate. Compounds 1-3 (Fig. 1) were evaluated for their capacity to inhibit the in vitro growth of three human tumor cell lines, MCF-7 (breast adenocarcinoma), NCI-H460 (non-small cell lung cancer) and SF-268 (CNS cancer). The indolic compounds $\mathbf{1}$ and $\mathbf{3}$ gave the best antiproliferative results but compound $\mathbf{1}$ was shown to be the most potent with $\mathrm{GI}_{50}(50 \%$ of cell growth inhibition) values ranging from $11-17 \mu \mathrm{M}$ in all cell lines studied [6].

These results suggested us to perform fluorescence studies of incorporation of compounds $\mathbf{1}-\mathbf{3}$ in lipid 
Fig. 1 Structure of heteroarylindoles $\mathbf{1}$ and $\mathbf{3}$ and heteroannulated indole 2

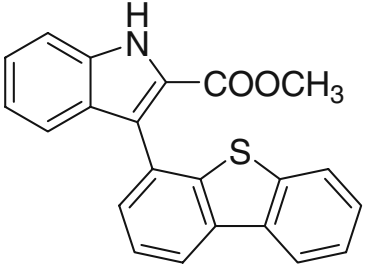

1<smiles>CC(=O)c1[nH]c2ccc3c4ccccc4sc3c2c1-c1ccccc1</smiles>

2<smiles>CC(=O)c1[nH]c2ccccc2c1-c1cccc2c1oc1ccccc12</smiles>

3 membranes. The photophysical properties in solution and in lipid aggregates of neutral phospholipid components of biological membranes, DPPC (dipalmitoyl phosphatidylcholine), DOPE (dioleoyl phosphatidylethanolamine) and Egg-PC (egg yolk phosphatidylcholine) were studied. Fluorescence (steady-state) anisotropy measurements were also performed to obtain further information about the behavior of the compounds in lipid membranes.

\section{Experimental}

Materials and methods

All the solutions were prepared using spectroscopic grade solvents and ultrapure water (Milli-Q grade). 1,2Dipalmitoyl-sn-glycero-3-phosphocholine (DPPC), 1,2Dioleoyl-sn-glycero-3-phosphoethanolamine (DOPE) and 1,2-Diacyl-sn-glycero-3-phosphocholine from egg yolk (Egg-PC) were purchased from Sigma-Aldrich (lipid structures are shown below).

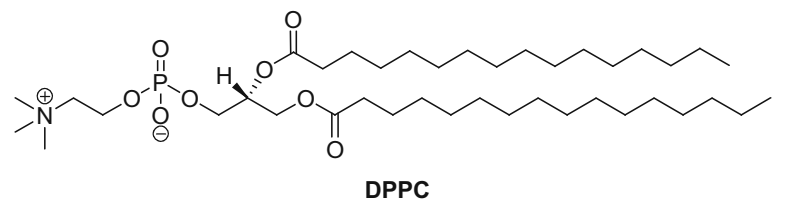

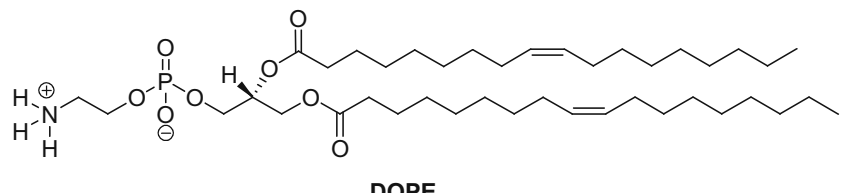

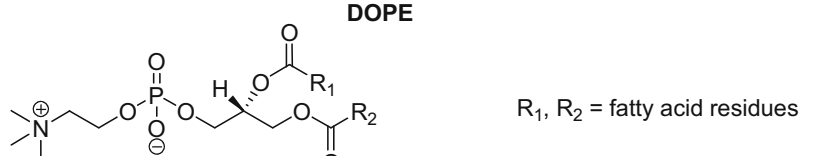

Egg-PC

For DOPE and Egg-PC membranes preparation, defined volumes of stock solutions of lipid (26.9 $\mathrm{mM}$ for DOPE and $34.5 \mathrm{mM}$ for Egg-PC) and compound ( $0.235 \mathrm{mM}$ for $\mathbf{1}$, $0.229 \mathrm{mM}$ for 2 and $0.282 \mathrm{mM}$ for 3 ) in ethanol were injected together, under vigorous stirring, to an aqueous buffer solution ( $10 \mathrm{mM}$ Tris, $1 \mathrm{mM}$ EDTA, $\mathrm{pH}=7.4)$, at room temperature. A similar procedure was adopted for
DPPC vesicles, but the injection of the required amounts of stock solutions of lipid $(50 \mathrm{mM})$ and compounds $\mathbf{1}, 2$ or 3 in ethanol was done at $60^{\circ} \mathrm{C}$, well above the melting transition temperature of DPPC $\left(\mathrm{ca} .41^{\circ} \mathrm{C}\right)$ [7]. In all cases, the final lipid concentration was $1 \mathrm{mM}$, with compounds $\mathbf{1}$, 2 or 3/lipid molar ratio of 1:500.

Spectroscopic measurements

Absorption spectra were recorded in a Shimadzu UV3101PC UV-Vis-NIR spectrophotometer. Fluorescence measurements were performed using a Spex Fluorolog 3 spectrofluorimeter, equipped with double monochromators in both excitation and emission and a temperature controlled cuvette holder. Fluorescence spectra were corrected for the instrumental response of the system. An excitation wavelength of $325 \mathrm{~nm}$ was used, near the lowest energy maximum (or shoulder) in the absorption spectrum of the compounds in all solvents studied.

For fluorescence quantum yield determination, the solutions were previously bubbled for 20 minutes with ultrapure nitrogen. The fluorescence quantum yields $\left(\Phi_{\mathrm{s}}\right)$ were determined using the standard method (eq. 1) $[8,9]$. 9,10-diphenylanthracene in ethanol was used as reference, $\Phi_{\mathrm{r}}=0.95[10]$.

$\Phi_{\mathrm{s}}=\frac{A_{\mathrm{r}} F_{\mathrm{s}} n_{\mathrm{s}}^{2}}{A_{\mathrm{s}} F_{\mathrm{r}} n_{\mathrm{r}}^{2}} \Phi_{\mathrm{r}}$

where $A$ is the absorbance at the excitation wavelength, $F$ the integrated emission area and $n$ the refraction index of the solvents used. Subscripts refer to the reference (r) or sample (s) compound.

\section{Results and discussion}

Photophysical properties of compounds 1, 2 and $\mathbf{3}$ in solution

The absorption and fluorescence properties of the 3(dibenzothien-4-yl)indole $\mathbf{1}$, the phenylbenzothienoindole 2 and the 3-(dibenzofur-4-yl)indole 3 were studied in several solvents. The maximum absorption $\left(\lambda_{\mathrm{abs}}\right)$ and emission wavelengths $\left(\lambda_{\mathrm{em}}\right)$, molar extinction coefficients 
$(\varepsilon)$ and fluorescence quantum yields $\left(\Phi_{\mathrm{F}}\right)$ of the three compounds are presented in Table 1. The normalized fluorescence spectra of compounds 1, 2 and $\mathbf{3}$ are shown in Figs. 2, 3 and 4, respectively. Examples of absorption spectra are displayed as insets.

The near-ultraviolet absorption of indole and their derivatives has been attributed to two strongly overlapping $\pi \rightarrow \pi^{*}$ transitions [11-13], with an average $\varepsilon$ value for unsubstituted indole of $5550 \mathrm{M}^{-1} \mathrm{~cm}^{-1}$, which also justifies its relatively high fluorescence quantum yield [14]. All the indole derivatives 1-3 have also a carboxylate group and it is known that many carbonyl compounds exhibit low fluorescence quantum yields due to the low-lying $n \rightarrow \pi^{*}$ state. In these new indole derivatives, it is possible that the electronic transitions $\pi \rightarrow \pi^{*}$ and $n \rightarrow \pi^{*}$ can be nearby in energy, resulting in state-mixing [15]. A predominance of $\pi \rightarrow \pi^{*}$ character could explain the relatively high $\varepsilon$ values $\left(\varepsilon>9 \times 10^{3} \mathrm{M}^{-1} \mathrm{~cm}^{-1}\right)$ for compounds 1-3 (Table 1 ).

In emission spectra, a significant red shift can be observed from cyclohexane to more polar solvents $(38 \mathrm{~nm}$ for compound $\mathbf{1}, 47 \mathrm{~nm}$ for compound $\mathbf{2}, 26 \mathrm{~nm}$ for compound 3 , from cyclohexane to methanol). In the absorption spectra, the red shifts are negligible for the three compounds (Table 1), indicating that solvent relaxation after photoexcitation plays an important role.

In polar solvents, a strong band enlargement and complete absence of vibrational structure is also observed (Figs. 2, 3 and 4), which is usually related to an intramolecular charge transfer (ICT) mechanism and/or to specific solvent effects [16]. This behavior was already observed in other indole

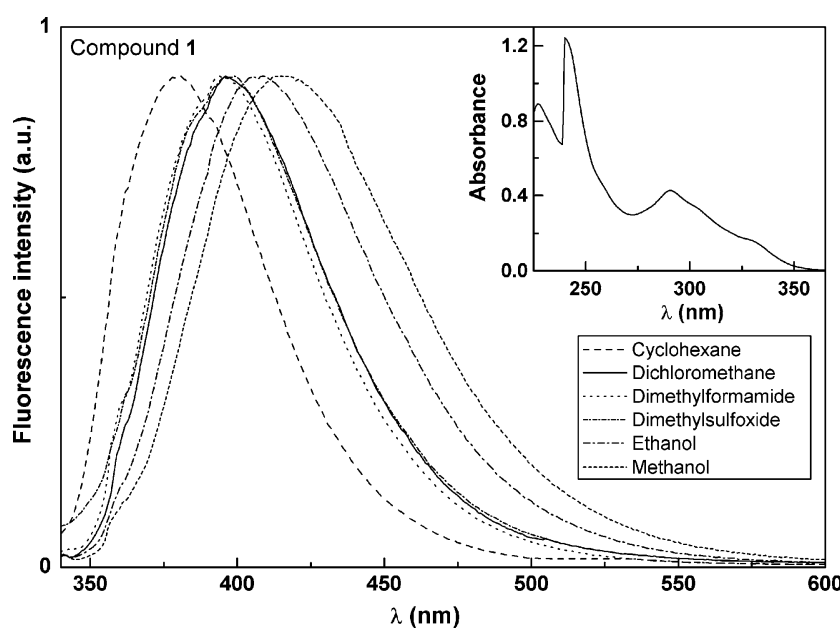

Fig. 2 Normalized fluorescence (at peak of maximum emission) spectra of $3 \times 10^{-6} \mathrm{M}$ solutions of 3-(dibenzothien-4-yl)indole 1 in several solvents $\left(\lambda_{\mathrm{exc}}=325 \mathrm{~nm}\right)$. Inset: Absorption spectrum of a $2 \times$ $10^{-5} \mathrm{M}$ solution of 1 in dichloromethane, as an example

derivatives previously obtained by us, namely the methyl 3arylindole-2-carboxylates [2] and the 1-heteroaryl-3 $\mathrm{H}$ benzothieno or benzofuroindole-2-carboxylates [3].

Solvatochromic shifts caused by general (not specific) solvent effects are often described by the Lippert-Mataga eq. (2), which relates the energy difference between absorption and emission maxima to the orientation polarizability, [16, 17]

$\bar{v}_{\mathrm{abs}}-\bar{v}_{\mathrm{fl}}=\frac{1}{4 \pi \varepsilon_{0}} \frac{2 \Delta \mu^{2}}{h c R^{3}} \Delta f+$ const

Table 1 Maximum absorption $\left(\lambda_{\mathrm{abs}}\right)$ and emission wavelengths $\left(\lambda_{\mathrm{em}}\right)$, molar extinction coefficients $(\varepsilon)$ and fluorescence quantum yields $\left(\Phi_{\mathrm{F}}\right)$ for compounds $\mathbf{1}, \mathbf{2}$ and $\mathbf{3}$ in several solvents

\begin{tabular}{|c|c|c|c|c|c|c|c|c|c|}
\hline \multirow[t]{2}{*}{ Solvent } & \multicolumn{3}{|c|}{$\lambda_{\mathrm{abs}} / \mathrm{nm}\left(\varepsilon / \mathrm{M}^{-1} \mathrm{~cm}^{-1}\right)$} & \multicolumn{3}{|c|}{$\lambda_{\mathrm{em}} / \mathrm{nm}$} & \multicolumn{3}{|l|}{$\Phi_{\mathrm{F}}{ }^{\mathrm{a}}$} \\
\hline & 1 & 2 & 3 & 1 & 2 & 3 & 1 & 2 & 3 \\
\hline \multirow[t]{3}{*}{ Cyclohexane } & $325 \operatorname{sh}\left(9.04 \times 10^{3}\right)$ & $321\left(1.21 \times 10^{4}\right)$ & & & & & & & \\
\hline & $290\left(2.45 \times 10^{4}\right)$ & $285\left(2.81 \times 10^{4}\right)$ & $290\left(2.74 \times 10^{4}\right)$ & 380 & 382 & 372 & 0.17 & 0.12 & 0.51 \\
\hline & $240\left(6.50 \times 10^{4}\right)$ & $257\left(3.28 \times 10^{4}\right)$ & $226\left(4.62 \times 10^{4}\right)$ & & & & & & \\
\hline \multirow[t]{3}{*}{ Dichloromethane } & $324 \operatorname{sh}\left(9.27 \times 10^{3}\right)$ & $322\left(1.54 \times 10^{4}\right)$ & & & & & & & \\
\hline & $291\left(2.14 \times 10^{4}\right)$ & $287\left(3.92 \times 10^{4}\right)$ & $291\left(2.42 \times 10^{4}\right)$ & 398 & 399 & 381 & 0.10 & 0.08 & 0.32 \\
\hline & $234\left(6.39 \times 10^{4}\right)$ & $257\left(4.08 \times 10^{4}\right)$ & $227\left(4.46 \times 10^{4}\right)$ & & & & & & \\
\hline \multirow[t]{2}{*}{ Dimethylformamide } & $325 \operatorname{sh}\left(1.10 \times 10^{4}\right)$ & $322\left(1.51 \times 10^{4}\right)$ & $290\left(3.10 \times 10^{4}\right)^{\mathrm{b}}$ & & & & & & \\
\hline & $290\left(2.21 \times 10^{4}\right)^{\mathrm{b}}$ & $288\left(4.08 \times 10^{4}\right)^{\mathrm{b}}$ & & 399 & 400 & 384 & 0.15 & 0.17 & 0.46 \\
\hline \multirow[t]{2}{*}{ Dimethylsulfoxide } & $325 \operatorname{sh}\left(1.08 \times 10^{4}\right)$ & $323\left(1.61 \times 10^{4}\right)$ & & & & & & & \\
\hline & $291\left(2.09 \times 10^{4}\right)^{\mathrm{b}}$ & $289\left(4.91 \times 10^{4}\right)^{\mathrm{b}}$ & $292\left(2.71 \times 10^{4}\right)^{\mathrm{b}}$ & 400 & 402 & 390 & 0.05 & 0.09 & 0.49 \\
\hline \multirow[t]{3}{*}{ Ethanol } & $325 \operatorname{sh}\left(1.07 \times 10^{4}\right)$ & $323\left(1.61 \times 10^{4}\right)$ & & & & & & & \\
\hline & $290\left(2.21 \times 10^{4}\right)$ & $287\left(4.70 \times 10^{4}\right)$ & $290\left(2.76 \times 10^{4}\right)$ & 408 & 420 & 393 & 0.14 & 0.12 & 0.47 \\
\hline & $233\left(6.94 \times 10^{4}\right)$ & $257\left(4.39 \times 10^{4}\right)$ & $225\left(4.96 \times 10^{4}\right)$ & & & & & & \\
\hline \multirow[t]{3}{*}{ Methanol } & $324 \operatorname{sh}\left(9.95 \times 10^{3}\right)$ & $323\left(1.41 \times 10^{4}\right)$ & & & & & & & \\
\hline & $289\left(2.13 \times 10^{4}\right)$ & $285\left(4.25 \times 10^{4}\right)$ & $290\left(2.59 \times 10^{4}\right)$ & 418 & 429 & 398 & 0.15 & 0.12 & 0.42 \\
\hline & $233\left(6.68 \times 10^{4}\right)$ & $255\left(3.99 \times 10^{4}\right)$ & & & & & & & \\
\hline
\end{tabular}

${ }^{\text {a }}$ Relative to 9,10-diphenylanthracene in ethanol $\left(\Phi_{\mathrm{r}}=0.95\right.$ [12]).

b Solvents cut-off: Dimethylformamide: $275 \mathrm{~nm}$; Dimethylsulfoxide: $270 \mathrm{~nm}$. sh: shoulder. 


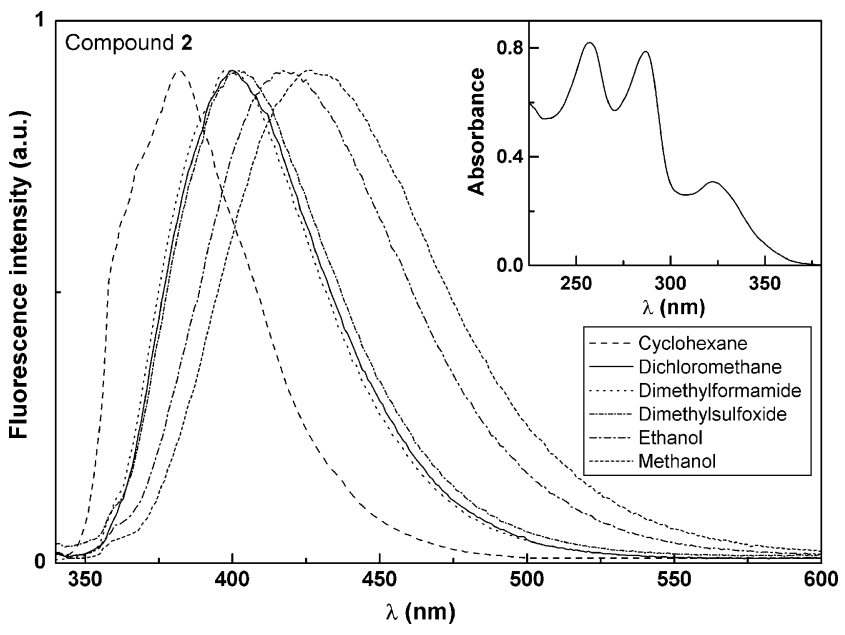

Fig. 3 Normalized fluorescence (at peak of maximum emission) spectra of $3 \times 10^{-6} \mathrm{M}$ solutions of phenylbenzothienoindole 2 in several solvents $\left(\lambda_{\mathrm{exc}}=325 \mathrm{~nm}\right)$. Inset: Absorption spectrum of a $2 \times$ $10^{-5} \mathrm{M}$ solution of $\mathbf{2}$ in dichloromethane, as an example

where $\bar{v}_{\mathrm{abs}}$ is the wavenumber of maximum absorption, $\bar{v}_{\mathrm{fl}}$ is the wavenumber of maximum emission, $\Delta \mu=\mu_{\mathrm{e}}-\mu_{\mathrm{g}}$ is the difference in the dipole moment of solute molecule between excited $\left(\mu_{\mathrm{e}}\right)$ and ground $\left(\mu_{\mathrm{g}}\right)$ states, $R$ is the cavity radius (considering the fluorophore a point dipole at the center of a spherical cavity immersed in the homogeneous solvent), and $\Delta f$ is the orientation polarizability given by (eq. 3):

$\Delta f=\frac{\varepsilon-1}{2 \varepsilon+1}-\frac{n^{2}-1}{2 n^{2}+1}$

where $\varepsilon$ is the static dielectric constant and $n$ the refractive index of the solvent.

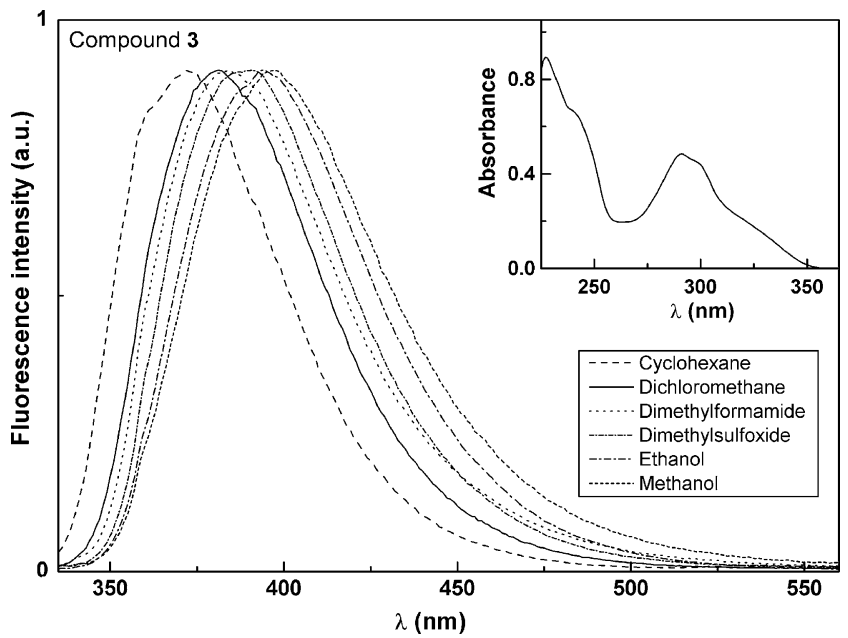

Fig. 4 Normalized fluorescence (at peak of maximum emission) spectra of $3 \times 10^{-6} \mathrm{M}$ solutions of 3-(dibenzofur-4-yl)indole 3 in several solvents $\left(\lambda_{\text {exc }}=325 \mathrm{~nm}\right)$. Inset: Absorption spectrum of a $2 \times$ $10^{-5} \mathrm{M}$ solution of $\mathbf{3}$ in dichloromethane, as an example
The Lippert-Mataga plot for compounds $\mathbf{1} \mathbf{- 3}$, shown in Fig. 5, is reasonably linear in non-protic solvents, alcohols exhibiting large positive deviations, especially for the heteroannulated indole 2 .

This behavior in alcohols can be due to specific solutesolvent interactions by hydrogen bonds, as all the three compounds have the capability of hydrogen bonding formation through the $\mathrm{NH}$ group (donor) and the ester group (acceptor). The $\mathrm{S}$ atom of the thiophene ring (for compounds 1 and 2) and the oxygen atom of the furan ring (in the case of compound 3) can also act as H-bond acceptors.

From ab initio molecular quantum chemistry calculations, the cavity radius $(R)$ and the ground state dipole moment $\left(\mu_{\mathrm{g}}\right)$ were determined for the three compounds (Table 2), through an optimized structure provided by GAMESS software [19], using a 3-21G(d) basis set [20] (Fig. 6). The optimized geometry of compound 2 shows that this molecule is almost completely planar, with the phenyl ring slightly out of the plane of the benzothienoindole tetracyclic moiety. On the contrary, the indole ring on compounds $\mathbf{1}$ and $\mathbf{3}$ is roughly perpendicular to the dibenzothiophene moiety (compound $\mathbf{1}$ ) or the dibenzofuran moiety (compound $\mathbf{3}$ ).

The excited state dipole moments, estimated from the Lippert-Mataga plots, are displayed in Table 2. The $\mu_{\mathrm{e}}$ values of the three molecules point to the presence of an intramolecular charge transfer (ICT) mechanism, more important for compound 1. Twisted intramolecular charge transfer states (TICT) usually exhibit significantly higher excited state dipole moments ( $\geq 20 \mathrm{D}$ ) [21] than those here obtained.

Figure 7 reports the HOMO and LUMO wavefunctions of the three compounds. For compound 2, the HOMOLUMO transition exhibits a charge transfer from the

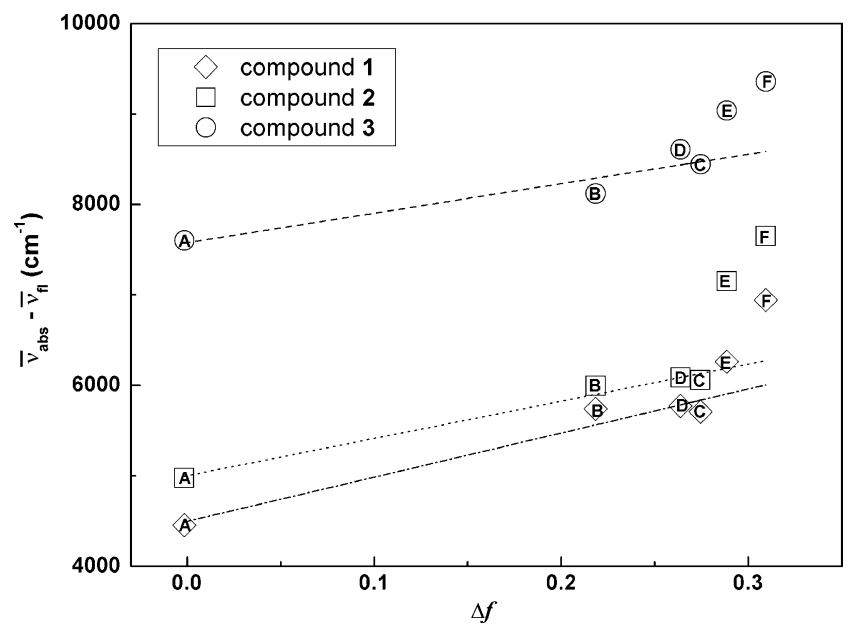

Fig. 5 Lippert-Mataga plots for compounds 1, 2 and 3: A: cyclohexane; B: dichloromethane; C: $N, N$-dimethylformamide; D: dimethylsulfoxide; E: ethanol; F: methanol (values of $\varepsilon$ and $n$ were obtained from ref. [18]) 
Table 2 Cavity radius $(R)$ and ground state dipole moments $\left(\mu_{\mathrm{g}}\right)$, obtained from theoretical calculations, and excited state dipole moments $\left(\mu_{\mathrm{e}}\right)$ calculated from the Lippert-Mataga plots

\begin{tabular}{|c|c|c|c|}
\hline Compound & $\begin{array}{c}\text { Cavity radius, } R \\
(\AA)\end{array}$ & $\begin{array}{c}\text { Ground state dipole } \\
\text { moment, } \mu_{\mathrm{g}}(\mathrm{D})\end{array}$ & $\begin{array}{c}\text { Excited state dipole } \\
\text { moment, } \mu_{\mathrm{e}}(\mathrm{D})\end{array}$ \\
\hline 3-(dibenzothien-4-yl)indole & 7.0 & 1.9 & 14.6 \\
\hline $\begin{array}{l}2-\mathrm{S} \\
\text { phenylbenzothienoindole }\end{array}$ & 6.4 & 1.4 & 11.8 \\
\hline 3-(dibenzofur-4-yl)indole & 6.6 & 2.6 & 12.3 \\
\hline
\end{tabular}

benzothienoindole moiety to the carboxylate group, the $\mathrm{S}$ atom having no electronic density at the LUMO. In case of compound 3, both ground and excited state electronic distributions are mainly localized at the indole moiety and the carbonyl group. The HOMO-LUMO transition shows a charge transfer from the indole ring to the carbonyl group of the ester, the dibenzofuran moiety having no contribution to this transition. However, for compound 1, the electronic density of HOMO is localized at the dibenzothiophene moiety and moves completely to the indole ring and to the carboxylate group upon the HOMO-LUMO transition. This justifies the higher excited state dipole moment obtained for

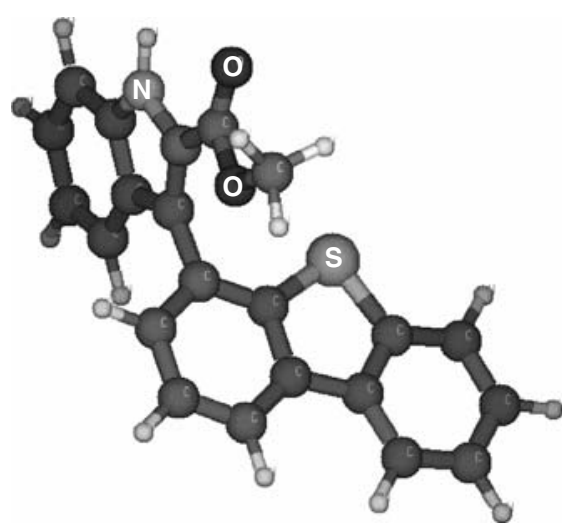

3-(dibenzothien-4-yl)indole 1

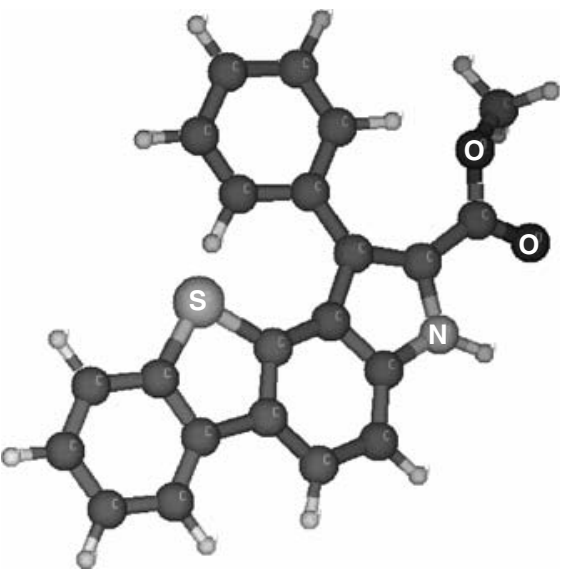

phenylbenzothienoindole 2

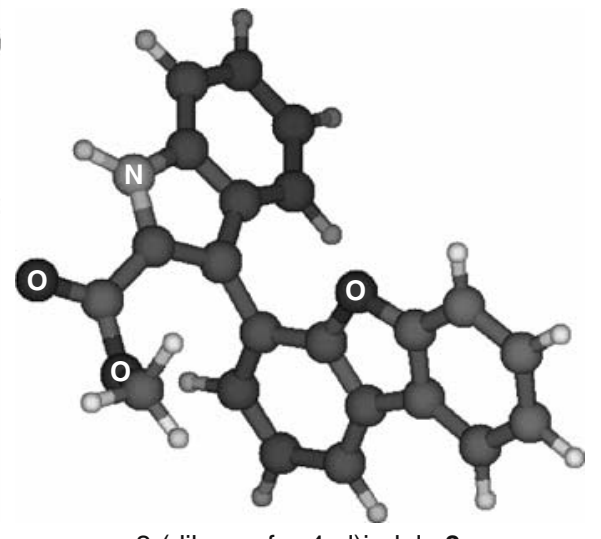

3-(dibenzofur-4-yl)indole 3

Fig. 6 Optimized structures of heteroarylindoles $\mathbf{1}$ and $\mathbf{3}$ and heteroannulated indole $\mathbf{2}$ (obtained by GAMESS software), with indication of S, N and $\mathrm{O}$ atoms 
Fig. 7 HOMO and LUMO electronic wavefunctions of heteroarylindoles $\mathbf{1}$ and $\mathbf{3}$ and heteroannulated indole 2
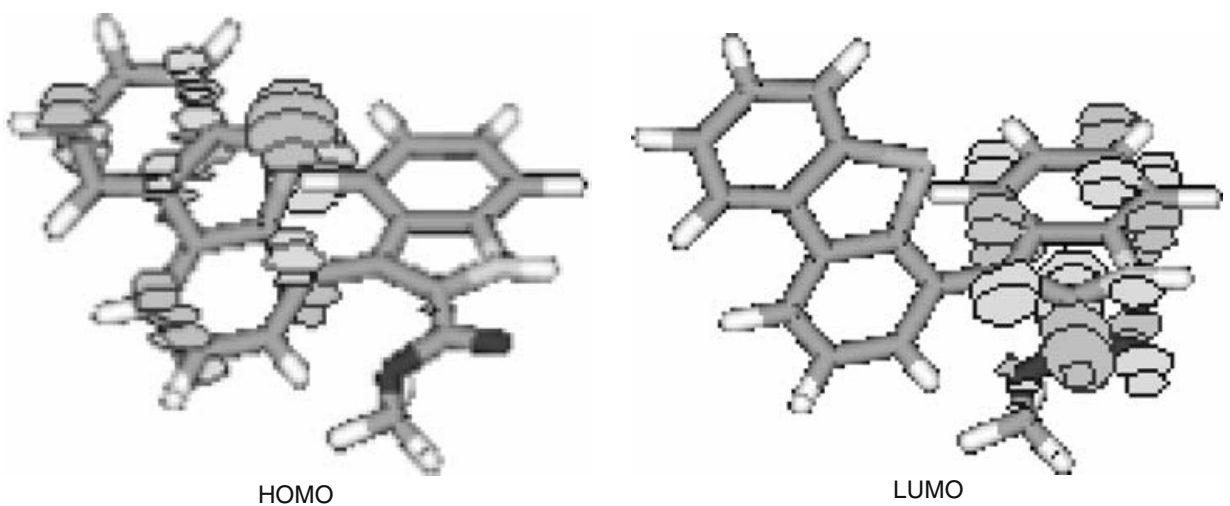

LUMO
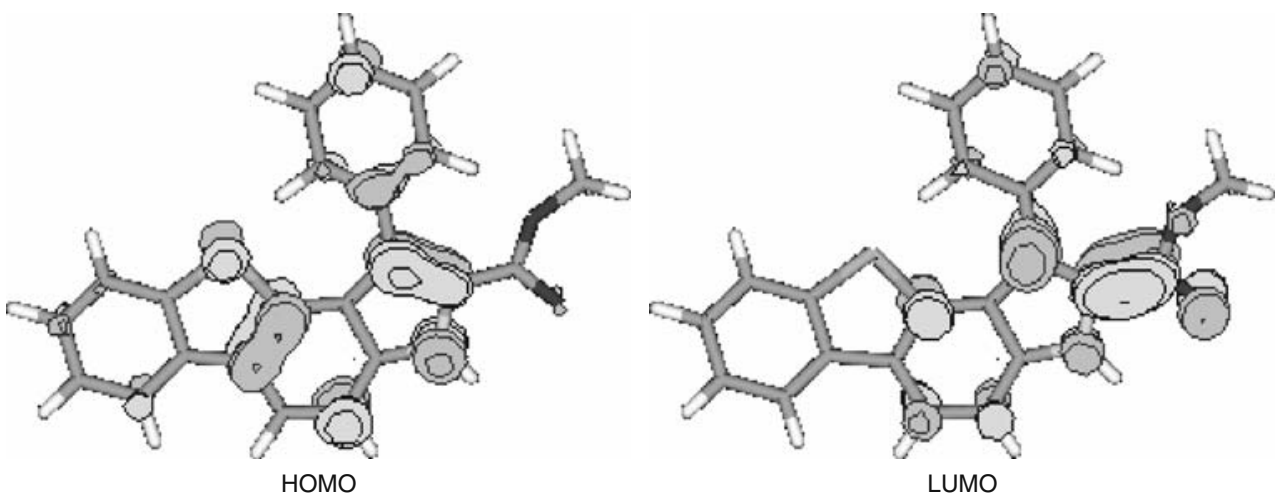

phenylbenzothienoindole 2
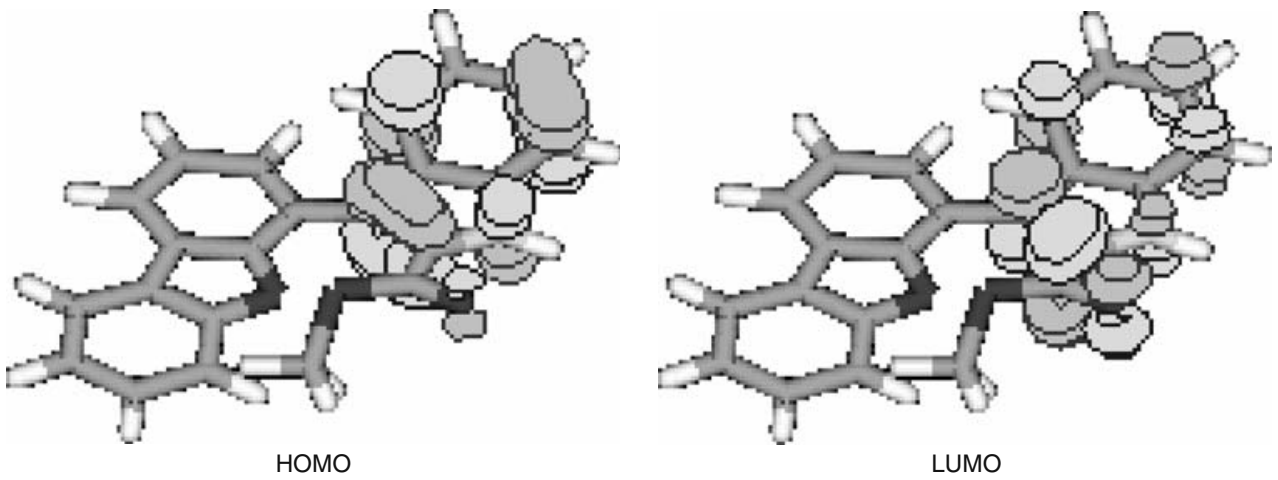

3-(dibenzofur-4-yl)indole 3

this compound and indicates a strong influence of the $\mathrm{S}$ heteroatom in the dibenzothiophene system when compared to the $\mathrm{O}$ in the dibenzofuran moiety of compound $\mathbf{3}$.

Compound $\mathbf{3}$ presents good fluorescence quantum yields in all solvents $\left(\Phi_{\mathrm{F}} \geq 0.32\right.$, Table 1$)$, while for compounds 1 and 2 , the values are relatively low $\left(\Phi_{\mathrm{F}} \leq 0.17\right)$. The decrease in fluorescence quantum yields observed for the latter compounds is justified by the presence of the $\mathrm{S}$ atom in the thiophene ring, which can promote the intersystem crossing process by enhancement of spin-orbit coupling interaction $[15,16]$, as observed for other indole derivatives $[2,3]$. The expected formation of hydrogen bonds between these compounds and protic solvents does not cause a decrease (or even an increase) of $\Phi_{\mathrm{F}}$ values in alcohols (Table 1), in contrast to what was observed for other indoles obtained by us [2].

Interaction of compounds $\mathbf{1 ,} \mathbf{2}$ and $\mathbf{3}$ with lipid membranes

Due to their promising antitumoral activity [6], photophysical studies of indoles $\mathbf{1 - 3}$ incorporated in lipid membranes were also performed. These studies are important to evaluate the interaction of the compounds with lipid membranes. It is also important to assess the localization of the compounds in lipid vesicles, pointing to drug delivery applications using liposomes. 
Different types of phospholipid molecules, DPPC, Egg$\mathrm{PC}$ and DOPE, were used for vesicle preparation. It is known that at room temperature, DPPC (16:0 PC) is in the ordered gel phase, where the hydrocarbon chains are fully extended and closely packed. Above the melting transition temperature, $\mathrm{T}_{\mathrm{m}}=41^{\circ} \mathrm{C}$ [7], DPPC attains the disordered liquid-crystalline phase. DOPE (18:1 PE) has a very low melting transition temperature $\left(\mathrm{T}_{\mathrm{m}}=-16{ }^{\circ} \mathrm{C}\right.$ [22]) and presents a lamellar bilayer to inverse hexagonal $\left(\mathrm{L}_{\alpha}-\mathrm{H}_{\mathrm{II}}\right)$ phase transition at $3.3{ }^{\circ} \mathrm{C}$ [23]. Finally, Egg-PC is a natural phospholipid mixture, where all molecules have the same polar head group (phosphatidylcholine) but several hydrocarbon chains, differing in length and degree of unsaturation. Egg-PC main components are 16:0 PC, 18:0 PC and 18:1 PC [24]. Therefore, at room temperature, Egg-PC is in the fluid liquid-crystalline phase.

The emission spectra of compounds $\mathbf{1 - 3}$ in lipid membranes are displayed in Figs. 8, 9 and 10. The maximum emission wavelengths (Table 3) of the three compounds indicate a environment of moderate polarity, slightly more polar for compound $3(v d$. Table 1). A small blue shift $(1-3 \mathrm{~nm})$ is observed for all compounds in DPPC at the rigid gel phase (at $25^{\circ} \mathrm{C}$ ) relative to the emission in lipids at fluid phases.

In homogeneous solution, the effect of increasing temperature in the fluorescence of these indolic compounds is a $\sim 20-30 \%$ reduction and a very small blue shift (2-3 nm) between $25{ }^{\circ} \mathrm{C}$ and $55{ }^{\circ} \mathrm{C}$. The insets of Figs. 8, 9 and 10 show the emission spectra in cyclohexane and ethanol at $55^{\circ} \mathrm{C}$, where it can also be seen that the spectral shape is roughly the same observed at $25^{\circ} \mathrm{C}$.

The red-shifted emission of compounds 1-3 observed in lipid membranes at fluid phases (DOPE and Egg-PC at

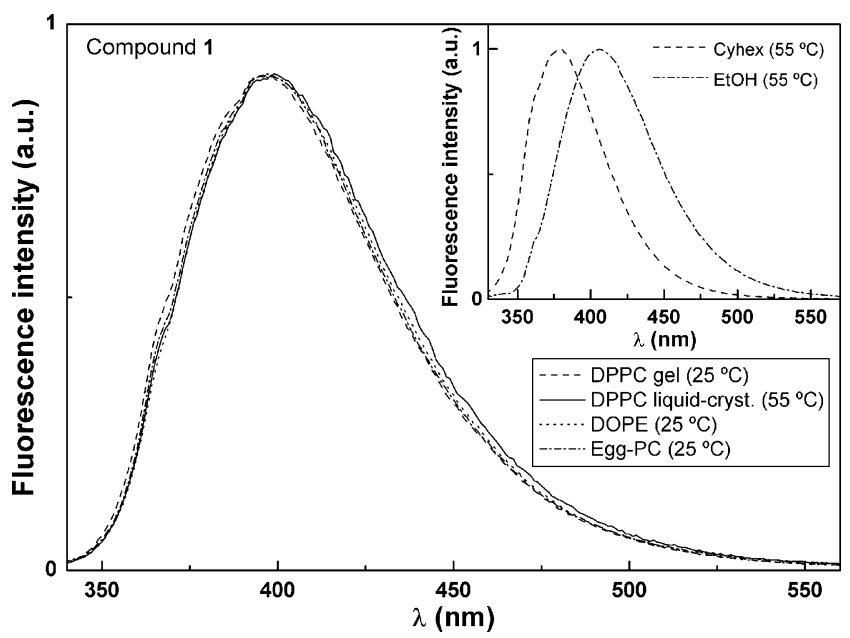

Fig. 8 Normalized fluorescence spectra of 3-(dibenzothien-4-yl) indole 1 in lipid membranes of DOPE, Egg-PC and DPPC $\left(\lambda_{\mathrm{exc}}=\right.$ $325 \mathrm{~nm}$ ). Inset: Normalized fluorescence spectra of compound $\mathbf{1}$ in cyclohexane (Cyhex) and ethanol $(\mathrm{EtOH})$ at $55^{\circ} \mathrm{C}$

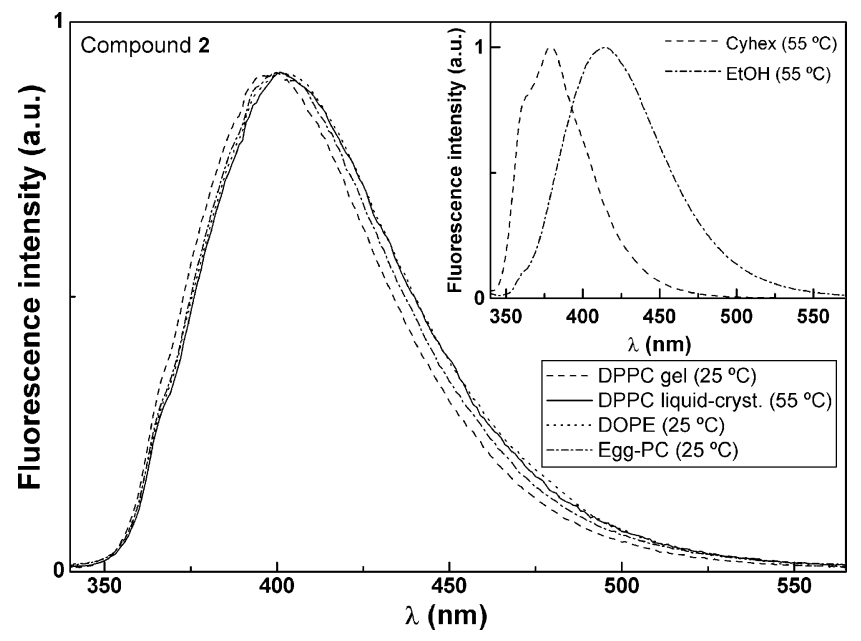

Fig. 9 Normalized fluorescence spectra of phenylbenzothienoindole 2 in lipid membranes of DOPE, Egg-PC and DPPC $\left(\lambda_{\text {exc }}=325 \mathrm{~nm}\right)$. Inset: Normalized fluorescence spectra of compound $\mathbf{2}$ in cyclohexane (Cyhex) and ethanol (EtOH) at $55^{\circ} \mathrm{C}$

$25^{\circ} \mathrm{C}$ and DPPC at $55^{\circ} \mathrm{C}$ ) points to a higher penetration of water molecules in the vesicle bilayer, as lipid hydrocarbon chains are randomly oriented and fluid. However, it is also possible that in fluid phases these indoles locate in a more polar environment.

Fluorescence anisotropy measurements can give further information about these molecules behavior in lipid membranes. The steady-state fluorescence anisotropy, $r$, is given by

$r=\frac{I_{\mathrm{VV}}-G I_{\mathrm{VH}}}{I_{\mathrm{VV}}+2 G I_{\mathrm{VH}}}$

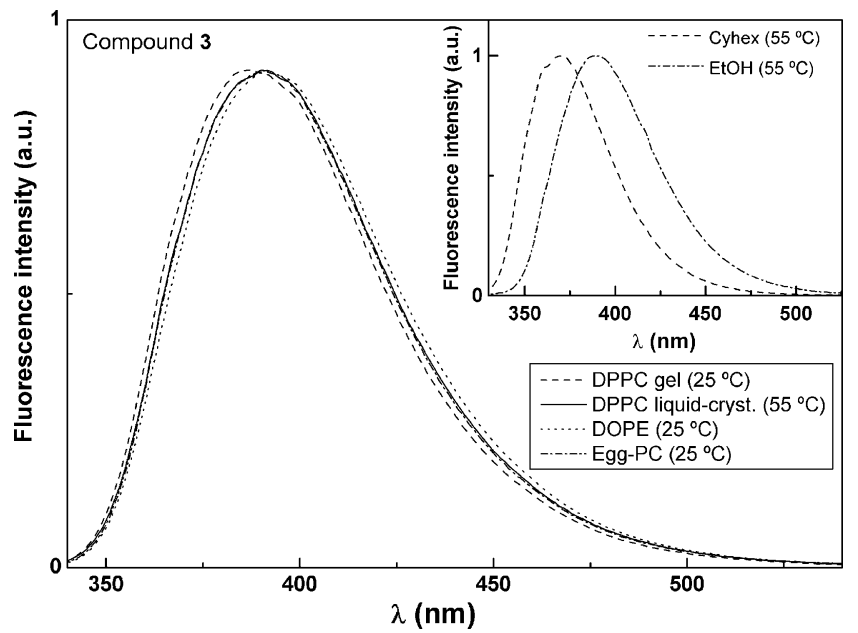

Fig. 10 Normalized fluorescence spectra of 3-(dibenzofur-4-yl)indole 3 in lipid membranes of DOPE, Egg-PC and DPPC $\left(\lambda_{\text {exc }}=325 \mathrm{~nm}\right)$. Inset: Normalized fluorescence spectra of compound 3 in cyclohexane (Cyhex) and ethanol (EtOH) at $55^{\circ} \mathrm{C}$ 
Table 3 Steady-state fluorescence anisotropy $(r)$ values, fluorescence quantum yields and maximum emission wavelengths $\left(\lambda_{\mathrm{em}}\right)$ of compounds $\mathbf{1 , 2}$ and $\mathbf{3}$ in lipid membranes. Values in ethylene glycol at room temperature are also shown for comparison

\begin{tabular}{|c|c|c|c|c|c|c|c|c|c|}
\hline & \multicolumn{3}{|c|}{ Compound 1} & \multicolumn{3}{|c|}{ Compound 2} & \multicolumn{3}{|c|}{ Compound $\mathbf{3}$} \\
\hline & $\lambda_{\mathrm{em}} / \mathrm{nm}$ & $\Phi_{\mathrm{F}}{ }^{\mathrm{a}}$ & $r$ & $\lambda_{\mathrm{em}} / \mathrm{nm}$ & $\Phi_{\mathrm{F}}{ }^{\mathrm{a}}$ & $R$ & $\lambda_{\mathrm{em}} / \mathrm{nm}$ & $\Phi_{\mathrm{F}}{ }^{\mathrm{a}}$ & $R$ \\
\hline $\operatorname{DPPC}\left(25^{\circ} \mathrm{C}\right)$ & 397 & 0.08 & 0.162 & 400 & 0.08 & 0.038 & 387 & 0.26 & 0.181 \\
\hline $\operatorname{DPPC}\left(55^{\circ} \mathrm{C}\right)$ & 399 & 0.02 & 0.115 & 401 & 0.01 & 0.027 & 390 & 0.04 & 0.089 \\
\hline DOPE $\left(25^{\circ} \mathrm{C}\right)$ & 399 & 0.09 & 0.091 & 401 & 0.08 & 0.013 & 391 & 0.27 & 0.062 \\
\hline Egg-PC $\left(25^{\circ} \mathrm{C}\right)$ & 397 & 0.07 & 0.156 & 401 & 0.08 & 0.029 & 390 & 0.28 & 0.151 \\
\hline Ethylene glycol $\left(25^{\circ} \mathrm{C}\right)$ & 422 & 0.09 & 0.116 & 434 & 0.08 & 0.022 & 400 & 0.31 & 0.097 \\
\hline
\end{tabular}

${ }^{\text {a }}$ Relative to 9,10-diphenylanthracene in ethanol $\left(\Phi_{\mathrm{r}}=0.95\right.$ [12]).

where $I_{\mathrm{VV}}$ and $I_{\mathrm{VH}}$ are the intensities of the emission spectra obtained with vertical and horizontal polarization, respectively (for vertically polarized excitation light), and $G=I_{\mathrm{HV}} / I_{\mathrm{HH}}$ is the instrument correction factor, where $I_{\mathrm{HV}}$ and $I_{\mathrm{HH}}$ are the emission intensities obtained with vertical and horizontal polarization (for horizontally polarized excitation light).

Steady-state anisotropy relates to both the excited-state lifetime and the rotational correlation time of the fluorophore [25],

$\frac{1}{r}=\frac{1}{r_{0}}\left(1+\frac{\tau}{\tau_{\mathrm{c}}}\right)$

where $r_{0}$ is the fundamental anisotropy, $\tau$ is the excitedstate lifetime and $\tau_{c}$ is the rotational correlation time.

The fluorescence steady-state anisotropies and fluorescence quantum yields of the three indoles in lipid aggregates are shown in Table 3. Anisotropy and quantum yield values in ethylene glycol at room temperature were also determined for comparison. The small anisotropy value obtained for compound $\mathbf{2}$ in this viscous solvent (Table 3 ) points to a low fundamental anisotropy for this molecule.

For each compound, the fluorescence quantum yields are similar in all lipid aggregates and in ethylene glycol at $25^{\circ} \mathrm{C}$. Therefore, variations in fluorescence anisotropy values at this temperature can be directly related to changes in the rotational correlation time of the fluorophore and, thus, to changes in the microviscosity of the surrounding medium of the fluorescent molecule. It can be observed for all compounds that $r$ values in DPPC at gel phase $\left(25^{\circ} \mathrm{C}\right)$ and in Egg-PC are higher than those obtained in ethylene glycol, indicating that compounds $\mathbf{1 - 3}$ are deeply located in the lipid bilayer. Indole 3 presents high anisotropy values in DPPC gel phase and in Egg-PC, similar to those of compound 1, despite the significantly higher fluorescence quantum yields, pointing to an even deeper penetration of compound $\mathbf{3}$ in these bilayers.

In DPPC at $55{ }^{\circ} \mathrm{C}$, a significant fluorescence quenching (Table 3 ) is observed for all compounds, as expected from the increase of the non-radiative deactivation pathways at higher temperatures. An increase of the steady-state anisotropy is predicted from a decrease of the excited-state lifetime (equation 5). However, all compounds show a significant decrease in anisotropy in DPPC at $55{ }^{\circ} \mathrm{C}$ (Table 3), showing that these indoles detect the phospholipid gel to liquid-crystalline phase transition and the associated decrease of microviscosity. Anisotropies obtained in DPPC fluid phase $\left(55^{\circ} \mathrm{C}\right)$ are roughly similar to the values in ethylene glycol at $25{ }^{\circ} \mathrm{C}$ (Table 3). Compound 3 exhibits a larger difference in anisotropy between the gel and the liquid-crystalline phase of DPPC. It is possible that, upon DPPC membrane fluidization, this compound locates in a more hydrated environment, as indicated by the slightly higher red shift in emission from the gel to the fluid phase (Table 3).

The phospholipid DOPE, at room temperature, adopts the inverse hexagonal phase, where the lipid molecules can adopt inverse curvature at the interface, allowing the chains to expand and at the same time reduce the headgroup area at the interface [26]. The lower anisotropy values measured in DOPE (Table 3) reflect the quite different geometry of self-organized DOPE aggregates, through the mentioned chain expansion. The emission spectra (Figs. 8, 9 and 10) indicate that these indoles feel a very similar environment in DOPE to that in DPPC at the liquid-crystalline phase.

Liposomes have been widely used to deliver anticancer agents, in order to reduce the toxic effects of the drugs when given alone or to increase the drug circulation time and effectiveness [27]. Considering that compounds 1, 2 and $\mathbf{3}$ are mainly located near the phospholipid tails and their antitumoral activity, previously shown [6], these studies are promising to the incorporation of these indoles in liposomes for controlled drug delivery systems.

\section{Conclusions}

The three potential antitumoral compounds studied, a 3(dibenzothien-4-yl)indole 1, a phenylbenzothienoindole 2 and a 3-(dibenzofur-4-yl)indole $\mathbf{3}$, show a solvent sensitive fluorescence emission and reasonable fluorescence quan- 
tum yields in all solvents studied, compound $\mathbf{3}$ exhibiting the higher $\Phi_{\mathrm{F}}$ values. The estimated excited state dipole moments point to an ICT character of the excited state, more pronounced for compound $\mathbf{1}$, confirmed by molecular quantum chemistry calculations.

Studies of the compounds incorporation in lipid aggregates of DPPC, DOPE and Egg-PC revealed that the three indolic compounds are deeply located in the lipid bilayer and are able to report differences between the gel and liquid-crystalline phases.

Considering the already proven anti-proliferative activity of human tumor cell lines exhibited by these molecules, the results obtained here show a promising utility of compounds 1-3 as antitumoral drugs, with the possibility of being transported in the hydrophobic region of liposomes.

Acknowledgements Foundation for the Science and Technology (FCT) - Portugal and FEDER, for financial support through Centro de Física and Centro de Química of Univ. Minho, through the Project POCI/QUI/59407/2004. A.S.A. acknowledges a post-doc. grant SFRH/BPD/24548/2005.

\section{References}

1. Abreu AS, Ferreira PMT, Queiroz M-JRP, Ferreira ICFR, Calhelha RC, Estevinho LM (2005) Synthesis of $\beta$-benzo[b] thienyldehydrophenylalanine derivatives by one-pot palladiumcatalyzed borylation and Suzuki coupling (BSC) and metalassisted intramolecular cyclization-Studies of fluorescence and antimicrobial activity. Eur J Org Chem 2951-2957. doi:10.1002/ ejoc. 200500040

2. Queiroz M-JRP, Abreu AS, Castanheira EMS, Ferreira PMT (2007) Synthesis of new 3-arylindole-2-carboxylates using $\beta, \beta$ diaryldehydroamino acids as building blocks. Fluorescence studies. Tetrahedron 63:2215-2222. doi:10.1016/j.tet.2006.12.084

3. Queiroz M-JRP, Castanheira EMS, Carvalho MSD, Abreu AS, Ferreira PMT, Karadeniz H, Erdem A (2008) New tetracyclic heteroaromatic compounds based on dehydroamino acids: photophysical and electrochemical studies of interaction with DNA. Tetrahedron 64:382-391. doi:10.1016/j.tet.2007.10.090

4. Castanheira EMS, Pinto AMR, Queiroz M-JRP (2006) Fluorescence of a Benzothienopyridopyrimidone in solution and in lipid vesicles. J Fluorescence 16:251-257. doi:10.1007/s10895-005-0050-Z

5. Queiroz M-JRP, Castanheira EMS, Pinto AMR, Ferreira ICFR, Begouin A, Kirsch G (2006) Synthesis of the first thieno- $\delta$ carboline. Fluorescence studies in solution and in lipid vesicles. J Photochem Photobiol Chem 181:290-296. doi:10.1016/j. jphotochem.2005.12.010

6. Queiroz M-JRP, Abreu AS, Carvalho MSD, Ferreira PMT, Nazareth N, Nascimento MSJ (2008) Synthesis of new heteroaryl and heteroannulated indoles from dehydrophenylalanines: Antitumor evaluation. Bioorg Med Chem 16:5584-5589. doi:10.1016/ j.bmc.2008.04.004

7. Lentz BR (1989) Membrane "fluidity" as detected by diphenylhexatriene probes. Chem Phys Lipids 50:171-190. doi:10.1016/ 0009-3084(89)90049-2
8. Demas JN, Crosby GA (1971) The measurement of photoluminescence quantum yields. A review. J Phys Chem 75:9911024. doi:10.1021/j100678a001

9. Fery-Forgues S, Lavabre D (1999) Are fluorescence quantum yields so tricky to measure? A demonstration using familiar stationery products. J Chem Educ 76:1260-1264

10. Morris JV, Mahaney MA, Huber JR (1976) Fluorescence quantum yield determinations. 9,10-Diphenylanthracene as a reference standard in different solvents. J Phys Chem 80:969-974. doi:10.1021/j100550a010

11. Creed D (1984) The photophysics and photochemistry of the nearUV absorbing amino-acids. 1. Tryptophan and its simple derivatives. Photochem. Photobiol 39:537-562

12. Albinsson B, Kubista M, Nordén B, Thulstrup EW (1989) NearUltraviolet electronic-transitions of the tryptophan chromophorelinear dichroism, fluorescence anisotropy, and magnetic circulardichroism spectra of some indole-derivatives. J Phys Chem 93:6646-6654. doi:10.1021/j100355a016

13. Lippert H, Ritze H-H, Hertel IV, Radloff W (2004) Femtosecond time-resolved analysis of the photophysics of the indole molecule. Chem Phys Lett 398, 526-531. doi:10.1016/j.cplett.2004.09.111

14. Tatischeff I, Klein R (1975) Influence of environment on excitation wavelength dependence of fluorescence quantum yield of indole. Photochem Photobiol 22:221-229. doi:10.1111/j.17511097.1975.tb06740.x

15. Turro NJ (1978) Modern Molecular Photochemistry. Benjamin/ Cummings Pub., Menlo Park California

16. Lakowicz JR (1999) Principles of Fluorescence Spectroscopy. Kluwer Academic/Plenum Press, New York

17. Mataga N, Kubota T (1970) Molecular Interactions and Electronic Spectra. Marcel Dekker, New York

18. Lide DR (ed) (2002) Handbook of Chemistry and Physics. 83th Edition, CRC Press, Boca Raton

19. Schmidt MW, Baldridge KK, Boatz JA, Elbert ST, Gordon MS, Jensen JH, Koseki S, Matsunaga N, Nguyen KA, Su S, Windus TL, Dupuis M, Montgomery JA (1993) General Atomic and Molecular Electronic Structure System. J Comput Chem 14:13471363. doi: $10.1002 /$ jcc. 540141112

20. Jensen F (1999) Introduction to Computational Chemistry. John Wiley \& Sons West Sussex, England

21. Grabowski ZR, Rotkiewicz K, Rettig W (2003) Structural changes accompanying intramolecular electron transfer: Focus on twisted intramolecular charge-transfer states and structures. Chem Rev 103:3899-4031. doi:10.1021/cr9407451

22. Silvius JR (1982) Thermotropic phase transitions of pure lipids in model membranes and their modifications by membrane proteins, in Lipid-Protein Interactions. John Wiley \& Sons, New York

23. Toombes GES, Finnefrock AC, Tate MW, Gruner SM (2002) Determination of $\mathrm{L}_{\alpha}-\mathrm{H}_{\mathrm{II}}$ Phase Transition Temperature for 1,2Dioleoyl-sn-Glycero-3-Phosphatidylethanolamine. Biophys J 82:2504-2510

24. Papahadjopoulos D, Miller N (1967) Phospholipid model membranes. I. Structural characteristics of hydrated liquid crystals. Biochim Biophys Acta 135:624-638. doi:10.1016/0005-2736(67) 90094-6

25. Valeur B (2001) Molecular Fluorescence-Principles and Applications. Wiley-VCH, Weinheim

26. Seddon JM (1990) Structure of the inverted hexagonal $\left(\mathrm{H}_{\mathrm{II}}\right)$ phase and non-lamellar phase transitions in lipids. Biochim Biophys Acta 1031:1-69

27. Banerjee R (2001) Liposomes Applications in medicine. J Biomater Appl 16:3-21. doi:10.1106/RA7U-1V9C-RV7C-8QXL 